EVS25

Shenzhen, China, Nov 5-9, 2010

\title{
Evaluation of Electric Vehicles based on Long-term Travel Activity Data of Passenger Cars
}

\author{
Yoshinori Kondo ${ }^{1}$, Hideki Kato ${ }^{1}$, Keisuke Matsuhashi ${ }^{1}$ \\ ${ }^{1}$ National Institute for Environmental Studies, 16-2 Onogawa, Tsukuba, Ibaraki 305-8506, kondos@nies.go.jp
}

\begin{abstract}
This study aimed to clarify whether currently available electric vehicles (EVs) could feasibly match the performance of gasoline-powered passenger cars with respect to the actual travel activity data collected for 18 gasoline-powered cars over the years 2006 and 2007 in Tsukuba in Japan. We examined 3 types of EV of different vehicle size and battery capacity, and calculated the running energy of each based on the vehicle specifications and actual speed pattern data. Auxiliary energy consumption such as that required for headlights at nighttime and air-conditioning on hot or cold days was added to the running energy. Supposing charging ability of $100 \mathrm{~V}$ and $8 \mathrm{~A}$ at home, when the energy consumed during a day did not exceed the initial available energy of the battery, we determined that the EV could replace a gasolinepowered vehicle for that day. Our calculations showed that an EV with a $9 \mathrm{kWh}$ battery could completely replace only 1 of the 18 cars, and EVs with a 16 or $24 \mathrm{kWh}$ battery could completely replace only 3 more. However, we found that an EV with a 16 or $24 \mathrm{kWh}$ battery could replace 17 out of the 18 cars if we accept that we may not be able to use the EV or may need to use fast charging 2 days a month. Simply increasing the battery capacity is not sufficient because the larger the EV's battery the bigger and heavier the vehicle and the longer the charging time needed. Though it is necessary to improve the charging ability at home, it might be a good policy that we think the use of other transportation rather than making an EV perfect so as to match the long-range travel needs one or two days a month.
\end{abstract}

Keywords: BEV, 100V charging, vehicle performance, passenger car

\section{Introduction}

Passenger cars in Japan account for about $10 \%$ of total national emissions of carbon dioxide. The introduction of low-carbon transportation and the use of low-carbon energy sources is considered essential to reducing these emissions, and electric vehicles (EVs) are considered to be one promising measure. Japanese automakers have been selling EVs since 2009, and other car companies are planning to introduce EVs in late
2010. EVs currently have shorter travel distances (about 90-160 km per charge) than vehicles with conventional engines. Rapid penetration of EVs into society is thought to be difficult from the viewpoint of high initial vehicle cost, limited percharge travel distances, and an insufficiency of fast charging stations. We surveyed the long-term vehicle travel activity of 68 passenger cars in a few Japanese cities in 2006-2007 [1], and collected data related to when, where, and for how long the vehicle was used. Our purpose in this paper is to 
clarify, on the basis of actual passenger car usage data, whether the performance of currently available EVs is adequate when the EV is not able to be charged at fast charging stations but relies on normal charging at home.

\section{Research Method}

\subsection{Specifications of EVs}

We examined 3 types of EV of different vehicle size and battery capacity, as shown in Table 1. Each of these EVs is currently sold and will be sold in Japan. The data from the 18 passenger cars used for the examination were collected over a year or more in Tsukuba in Japan, and each vehicle was used at least 120 days a year [1].

Table 1: Vehicle specifications

\begin{tabular}{|c|c|c|c|}
\hline \multirow{2}{*}{} & \multicolumn{3}{|c|}{ Electric vehicle } \\
\cline { 2 - 4 } & $\mathrm{V} 1$ & $\mathrm{~V} 2$ & $\mathrm{~V} 3$ \\
\hline Weight $(\mathrm{kg})$ & 1000 & 1100 & 1400 \\
\hline Dimension $(\mathrm{mm})$ & \multicolumn{2}{|c|}{ W1470 $\times$ H1630 } & $\mathrm{W} 1770 \times \mathrm{H} 1550$ \\
\hline Vehicle type & \multicolumn{2}{|c|}{ Mini wagon } & Compact sedan \\
\hline $\begin{array}{c}\text { Number of } \\
\text { passengers }\end{array}$ & \multicolumn{2}{|c|}{4} & 5 \\
\hline $\begin{array}{c}\text { Coefficient of } \\
\text { friction: } \mu\end{array}$ & \multicolumn{3}{|c|}{0.012} \\
\hline $\begin{array}{c}\text { Coefficient of } \\
\text { air } \\
\text { resistance: } C_{d}\end{array}$ & 0.5 & 0.34 \\
\hline $\begin{array}{c}\text { Battery capacity } \\
(\mathrm{kWh})\end{array}$ & 9 & 16 & 24 \\
\hline
\end{tabular}

\subsection{Energy consumed to move a vehicle}

The flow chart in Figure 1 shows the processes of our examination. The energy $\mathrm{P}(\mathrm{t}) \quad[\mathrm{W}]$ consumed to propel a vehicle was calculated from both the vehicle specifications and the second-by-second speed pattern data by using formulas (1) through (6).

$$
P(t)=R(t) V(t)
$$

where $R(t)$ is running resistance $[\mathrm{N}]$ and $V(t)$ is vehicle speed $\left[\mathrm{ms}^{-1}\right]$.

$$
R(t)=R_{r}+R_{l}(t)+R_{a}(t)+R_{s}(t)
$$

where $R_{r}$ is frictional resistance, $R_{l}$ is air resistance, $R_{a}$ is acceleration resistance, and $R_{S}$ is resistance by road gradient.

$$
R_{r}=\mu M g
$$

where $\mu$ is the coefficient of friction $\left[\mathrm{Nm}^{-1} \mathrm{~s}^{2} \mathrm{~kg}^{-1}\right]$, $M$ is vehicle mass $[\mathrm{kg}]$, and $g$ is the gravitational constant $\left[9.8 \mathrm{~ms}^{-2}\right]$.

$$
R_{l}(t)=\rho C_{d} S V(t)^{2} / 2
$$

where $\rho$ is air density $\left[\mathrm{kgm}^{-3}\right], C_{d}$ is the coefficient of air resistance, and $S$ is projection area $\left[\mathrm{m}^{-2}\right]$.

$$
R_{a}(t)=(M+\delta M) \alpha(t)
$$

where $\delta M$ is equivalent mass of rotating parts [kg] and $\alpha(t)$ is acceleration $\left[\mathrm{ms}^{-2}\right]$.

$$
R_{s}(t)=M g \sin \theta(t)
$$

where $\theta(t)$ is road inclination [radian].

The running energy consumption $E^{T}$ required for the use of a car is calculated as

$$
E^{T}=\sum_{t=0, P>0}^{T} P(t)
$$

where $T$ is running time of each trip [s].

\subsection{Indirect energy consumption when using a car}

We also calculated the indirect energy consumption, which means the energy not related to propelling the vehicle (Table 2). The energy

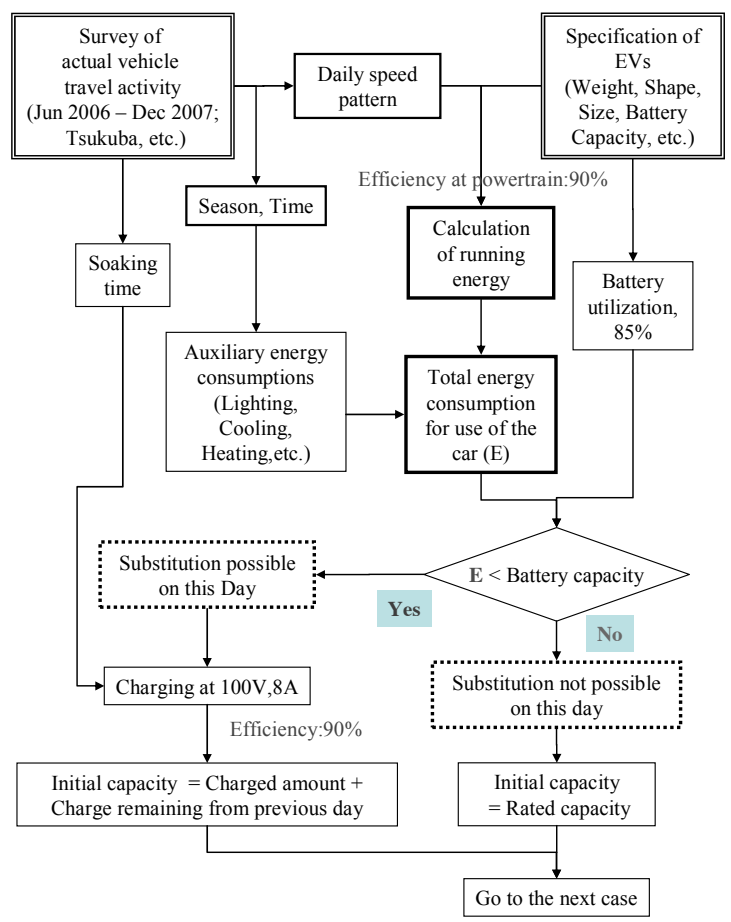

Figure 1: Flow chart of calculation process 
consumed by air-conditioning and cabin heating were assumed to be proportional to the running energy [2]. The energy used by lights at nighttime was calculated by multiplying a constant $200 \mathrm{~W}$ output by the period that the car is used. The decrease in battery performance that occurs in low-temperature environments was also estimated as a proportional increase in the running energy $\mathrm{E}^{\mathrm{T}}$.

Total daily energy consumption was derived from these energy consumptions by trips. Days when the EV could be used as an alternative to a gasoline-powered vehicle were determined by comparing the daily energy consumption with the initially available battery capacity. The battery capacity varied according to the period between the last use on a particular day and the first use on the following day (soaking time). The battery was assumed to be charged $(100 \mathrm{~V}, 8 \mathrm{~A})$ over the available soaking time, with a charging efficiency of $90 \%$. The efficiency of the power train was set to $90 \%$. Fifteen percent of battery capacity was assumed to be unused.

\section{Results and Discussion}

\subsection{How many vehicles could be replaced?}

Table 3 shows the periods over which the 18 cars were surveyed previously [1] and the percentage of days we estimate that each car's driving performance could be matched by each of the EVs. A mini-sized EV with $9 \mathrm{kWh}$ battery (V1) could completely replace only 1 of the 18 vehicles (Z31). If we consider a $16 \mathrm{kWh}$ minisized EV (V2) or a $24 \mathrm{kWh}$ compact EV (V3), the number of substitutions increased to 3 more vehicles.

Table 2 : Assumptions for energy consumption not related to the energy required to move a vehicle

\begin{tabular}{|c|c|}
\hline $\begin{array}{c}\text { Miscellaneous energy } \\
\text { consumption }\end{array}$ & Calculation method \\
\cline { 2 - 2 } Air conditioner & $\mathrm{E}^{\mathrm{T}} * 0.5$ \\
\cline { 2 - 2 } & ${\mathrm{June} 1^{\text {st }}-\text { September } 30^{\text {th }}}^{*} \mathrm{E}^{\mathrm{T}} * 0.2$ \\
\hline \multirow{2}{*}{ Heater } & November $1^{\text {st }}-$ February $28^{\text {th }}$ \\
\cline { 2 - 2 } & $200 \mathrm{~W}{ }^{*}$ Trip time \\
\hline \multirow{2}{*}{ Lighting } & Sunset - Sunrise \\
\cline { 2 - 2 } Low temperature & $\mathrm{E}^{\mathrm{T}} * 0.1$ \\
\cline { 2 - 2 } & November $1^{\text {st }}-$ April $30^{\text {th }}$ \\
\hline \multirow{2}{*}{}
\end{tabular}

Table 3: Rate of substitution by kind of EV

\begin{tabular}{|c|c|c|c|c|c|c|}
\hline \multirow[b]{2}{*}{$\begin{array}{l}\text { User } \\
\text { ID }\end{array}$} & \multicolumn{2}{|c|}{ Survey Period } & \multirow{2}{*}{$\begin{array}{c}\text { Number } \\
\text { of } \\
\text { Available } \\
\text { Data }\end{array}$} & \multicolumn{3}{|c|}{ Ratio of Substitution } \\
\hline & Start & Finish & & $\begin{array}{c}\mathrm{V} 1 \\
9 \mathrm{kWh}, \\
1000 \mathrm{~kg}\end{array}$ & $\begin{array}{c}\mathrm{V} 2 \\
16 \mathrm{kWh}, \\
1100 \mathrm{~kg}\end{array}$ & $\begin{array}{c}\mathrm{V} 3 \\
24 \mathrm{kWh}, \\
1400 \mathrm{~kg}\end{array}$ \\
\hline $\mathrm{Z1}$ & 2006.7 & 2007.12 & 484 & $88.0 \%$ & $97.3 \%$ & $98.1 \%$ \\
\hline $\mathrm{Z} 2$ & 2006.7 & 2007.10 & 359 & $90.0 \%$ & $95.3 \%$ & $96.7 \%$ \\
\hline $\mathrm{Z3}$ & 2006.7 & 2007.12 & 317 & $97.2 \%$ & $98.7 \%$ & $98.7 \%$ \\
\hline $\mathrm{Z} 4$ & 2006.7 & 2007.12 & 495 & $93.7 \%$ & $97.2 \%$ & $97.8 \%$ \\
\hline $\mathrm{Z} 5$ & 2006.6 & 2007.12 & 425 & $90.6 \%$ & $93.6 \%$ & $94.8 \%$ \\
\hline Z6 & 2006.6 & 2007.11 & 127 & $95.3 \%$ & $98.4 \%$ & $98.4 \%$ \\
\hline $\mathrm{Z} 8$ & 2006.10 & 2007.12 & 248 & $87.5 \%$ & $98.4 \%$ & $98.8 \%$ \\
\hline Z9 & 2006.6 & 2007.12 & 335 & $97.6 \%$ & $98.8 \%$ & $98.8 \%$ \\
\hline Z21 & 2006.11 & 2007.12 & 263 & $94.3 \%$ & $95.1 \%$ & $97.0 \%$ \\
\hline Z22 & 2006.11 & 2007.12 & 360 & $93.3 \%$ & $97.2 \%$ & $97.8 \%$ \\
\hline Z23 & 2006.11 & 2007.12 & 168 & $89.3 \%$ & $93.5 \%$ & $93.5 \%$ \\
\hline Z24 & 2006.11 & 2007.12 & 329 & $95.7 \%$ & $100.0 \%$ & $100.0 \%$ \\
\hline Z25 & 2006.11 & 2007.12 & 166 & $78.3 \%$ & $81.3 \%$ & $84.9 \%$ \\
\hline Z26 & 2006.12 & 2007.9 & 234 & $90.2 \%$ & $93.2 \%$ & $94.9 \%$ \\
\hline Z28 & 2006.12 & 2007.12 & 325 & $96.6 \%$ & $99.4 \%$ & $99.7 \%$ \\
\hline $\mathrm{Z} 31$ & 2007.1 & 2007.12 & 146 & $100.0 \%$ & $100.0 \%$ & $100.0 \%$ \\
\hline $\mathrm{Z} 32$ & 2007.1 & 2007.12 & 254 & $98.0 \%$ & $100.0 \%$ & $100.0 \%$ \\
\hline Z33 & 2007.5 & 2007.12 & 191 & $98.4 \%$ & $100.0 \%$ & $100.0 \%$ \\
\hline
\end{tabular}

Figure 2 shows the percentage of improvement of $\mathrm{V} 2$ and $\mathrm{V} 3$ over V1 in matching the daily demands of the 18 gasoline-powered vehicles. Although a relatively large difference was found with Z25, generally the difference in replacement potential between V2 and V3 was very small. The larger the battery capacity and the more space for people that the EV has, the larger and heavier the vehicle is and the longer the charging time needs to be. This means that an increase in battery capacity does not always translate to an improvement in distance per charge.

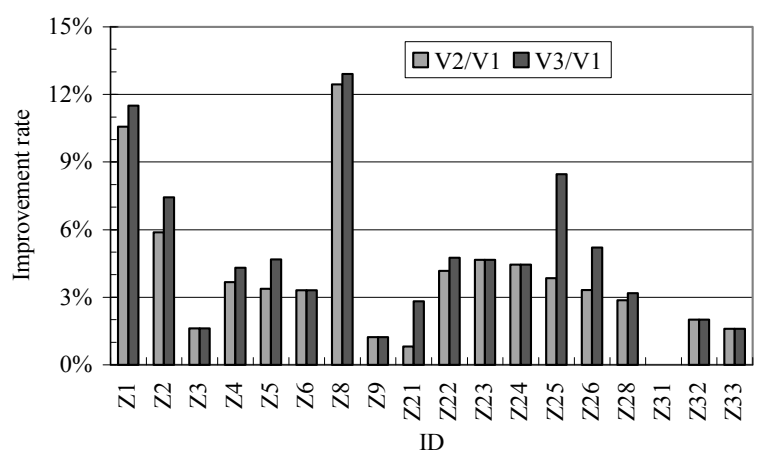

Figure 2: Improvement in replacement potential compared with V1 


\subsection{Case of complete replacement of a car with an EV}

Of the 18 surveyed cars, Z31 was the only one whose usage could be completely matched by a V1 type EV. Z31's original activity data (Figures 3 and 4) show that Z31 had a maximum daily travel distance of $34 \mathrm{~km}$, a monthly travel distance of from 68 to $192 \mathrm{~km}$, and an annual travel distance of $1599 \mathrm{~km}$. The average frequency of use was 12.2 times a month. As for soaking times, about $64 \%$ of soaking times were 24 hours or more. Short daily travel distances, infrequent use of the car, and long soaking times made Z31 replaceable. The results also suggested that the battery capacity could be reduced to half of the current V1 specification and still satisfy Z31's usage demands.

\subsection{Cases where replacement is difficult}

Even a V3 type EV with $24 \mathrm{kWh}$ of battery capacity could only satisfy around $80 \%$ of car Z25's demand. To clarify the reasons for this, we examined Z25's original travel activity data (Figures 5 and 6 ). We found that $15 \%$ of daily travel distances were beyond $100 \mathrm{~km}$. These

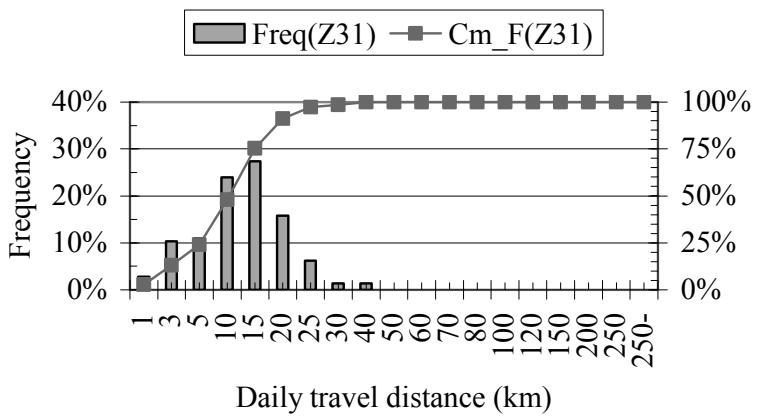

Figure 3: Travel characteristics for Z31 from the survey [1] $(100 \%$ of daily travel distance was within $40 \mathrm{~km})$ *Cm_F means "cumulative frequency"

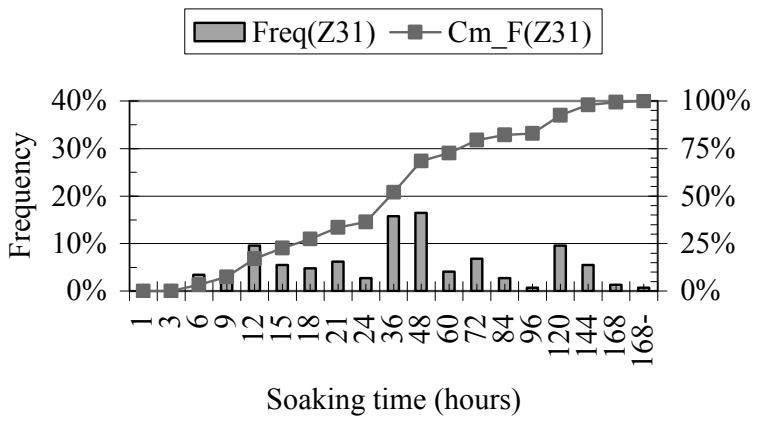

Figure 4: Soaking time distribution for Z31 (64\% of soaking times was longer than 24 hours) distances occurred frequently on weekends, and the car was repeatedly driven over $100 \mathrm{~km}$ a day for a week or more in May 2007. To match this car use and achieve complete replacement, an EV would need to have more batteries installed. But this option is not realistic because of increased purchase cost and weight. It would also necessitate longer charging times. At present, it is not possible to replace Z25 with an EV without also utilizing fast charging or a battery exchange. However, even if those methods are available, consumers' acceptance for fast charging or battery exchange has to be investigated.

\subsection{To increase the number of vehicles replaced by EVs}

\subsubsection{Lowering of substitution threshold}

Studies of human mobility show that a person follows a predictable daily pattern of movements up to $93 \%$ of the time [3]. In the light of this finding, we re-examined the number of vehicles that could be replaced by EVs. By taking a substitution rate of $\geq 93 \%$ rather than $100 \%$, V1 type EVs could replace 10 out of the 18 vehicles shown in Table 3, and V2 and V3 type EVs could replace 13 . Furthermore, if we regard $93 \%$ as the

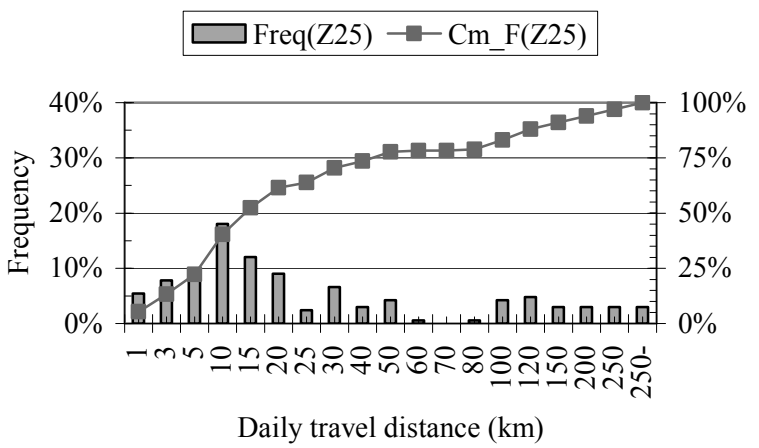

Figure 5: Travel characteristics for Z25

( $20 \%$ of daily travel distance was beyond $100 \mathrm{~km}$ )

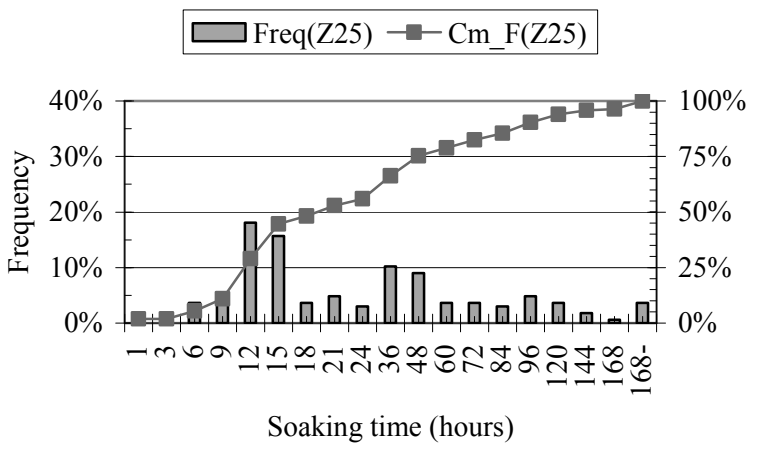

Figure 6: Soaking time distribution for Z25 (around $50 \%$ of soaking times between 18 and 21 hours) 
threshold and the EV is not used 2 days a month or if we accept the use of fast charging 2 days a month, then the number of vehicles replaced by EVs increased to 11 vehicles for V1 and 17 for V2 and V3. Therefore, almost all vehicles could be replaced by EVs with $16 \mathrm{kWh}$ of battery capacity.

On the other hand, in order to spread current EVs, alternative measures need to be considered and prepared. For example, installation of quick charge systems, or enabling the EV user to use an engine vehicle at a low price for a long travel. Furthermore, it might be effective that people think the method of realizing the purpose of their move without a car.

\subsubsection{Use reduction of air-conditioning}

Increased battery capacity results in a heavier vehicle, higher initial purchase price, and longer charging time. Some EVs now available in Japan do not come equipped with devices such as airconditioner or heater suited for comfortable driving. We examined the substitution rates with and without these devices for a V1 type EV and found that only 2 vehicles, Z1 and Z8, showed any notable increase, of $6.6 \%$ and $8.1 \%$, respectively. If air-conditioning is not used while driving, these 2 vehicles might be replaced with a V1 type EV. As for Z32 and Z33, their substitution rates increased to $100 \%$. As the result of calculation, it was clarified that 13 of 18 vehicles could replace with a $9 \mathrm{kWh} \mathrm{EV}$. If the EV driver accepts the slight decrease of comfortableness and reduces the use of airconditioning, the substitution rate of EVs can be improved.

Based on the actual travel activity data examined here, we found that substitution rate depended mostly on the daily travel distance, with auxiliary energy consumption contributing relatively little.

\section{Conclusions}

The feasibility of replacing conventional cars with currently available EVs was realistically examined on the basis of actual long-term vehicle use data collected in Tsukuba city during 2006 and 2007. Of the 18 vehicles examined, only 1 could be fully replaced by a mini-size 9 $\mathrm{kWh}$ EV. That particular car had short daily travel distances, infrequent use, and long soaking times. Mini-size $16 \mathrm{kWh}$ and compact $24 \mathrm{kWh}$ EVs could replace 4 of the 18 cars. However, if we accept the use of fast charging or no use of
EV two days a month, almost all vehicles could be replaced with mini-size $16 \mathrm{kWh}$ EV or compact 24 kWh EV.

Merely increasing battery capacity will not necessarily increase the substitution rate because the larger the battery capacity is, the larger and heavier the EV is and the longer the charging time need. Though it is necessary to improve the charge ability at home, it might be a good policy that we think the use of other transportation rather than make an EV perfect so as to match the long-range travel needs one or two days a month.

\section{Acknowledgments}

This work was supported by the Environment Research and Technology Development Fund of the Ministry of the Environment, Japan (E0904[2009-2010]).

\section{References}

[1] S. Kobayashi edited, Research on reduction of environmental load by a review of daily use transportation, Report of Special Research Project of the National Institute for Environmental Studies (in Japanese), SR-792008, 2008.

[2] T. Tateuchi, Private Communication.

[3] Chaoming Song, Zehui Qu, Nicholas Blumm, Albert-László Barabási, Limits of Predictability in Human Mobility, Science, Vol. 327, No. 5968, 2010, pp: 1018-1021.

\section{Authors}

\section{Dr of Eng., Yoshinori Kondo}

National Institute for Environmental Studies, Japan

Tel: +81-29-850-2441

Fax: +81-29-850-2964

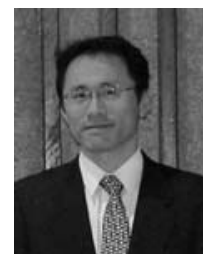

Email: kondos@nies.go.jp

Senior Researcher, Social and Environmental Systems Division; Interests in EVs, electric or humanpowered mobility, public transportation, and human health issues. 
Dr of Eng., Hideki Kato

National Institute for

Environmental Studies, Japan

Tel: $+81-29-850-2516$

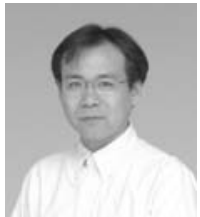

Fax: +81-29-850-2572

Email: kato.hideki@nies.go.jp

Post Doctoral Fellow,

Transportation and Urban Environment Section, Social and Environmental Division.

Dr of Eng., Keisuke Matsuhashi National Institute for Environmental Studies, Japan

Tel: $+81-29-850-2511$

Fax: +81-29-850-2572

Email: matuhasi@nies.go.jp

Senior Researcher, Transportation and Urban Environment Section,

Social and Environmental Systems Division. 